\title{
RFID: Chromogenic Polymer Opal Film with Seal Could be Adopted as a Sensitive and Effective Technology to Fight against Counterfeit Drugs
}

\author{
Tejpreet Chadha* and Ralph Ferguson
}

Texas Tech University, Box 43131, Lubbock, TX 79409, USA

\begin{abstract}
Counterfeit drugs have emerged as a global problem. Though, RFID (Radio Frequency Identification) technology increased security of the supply chain for drugs and consumer goods, prohibitive cost limited wide-spread acceptance globally by pharmaceutical companies. The approach to use chromogenic material with polymer opal films can be adopted as a low cost sensitive and effective tool to reduce counterfeit drugs. The color change response with the seal on the package provides a visual warning that can be detected by consumers or government regulatory personnel through observation. The packaging includes a film that would play an important role to enhance security and communicate with consumers through color change. As another tool in the arsenal to curtail counterfeit drug production and sale, chromogenic polymer opal film deserves attention by manufacturers as well as government procurement agencies.
\end{abstract}

Keywords: Counterfeit drugs; Degraded drugs; Chromogenic; Polymer opal film

\section{Introduction}

Counterfeiting established a global problem that resulted in deliberate supply chain corruption where degraded drugs led to therapeutic failures and deaths. The active ingredient in counterfeit drugs replaced by lesser quantity of the active chemical agent, sugar, chalk and sometimes toxic compounds that counterfeiters can increase their profit selling the degraded product at a lower price. In many cases, expired drugs are re-labeled and repackaged to mask the expiration date. The counterfeiters select drugs that are less likely to be reported e.g. Viagra. The associate director at Pfizer in Europe reported that the profits from counterfeit Viagra could be ten times higher than that of the street drug heroin [1]. The WHO reports that $60 \%$ drugs that are counterfeited belong to most popular therapeutic categories e.g. antibiotics, hormones, analgesics, steroids, and antihistamines [1-3]. The recent report by Food and Drug Administration (FDA) has shown that surgical mesh has also been counterfeited [2]. The drugs that have been counterfeited in the past are Lipitor, Procrit, Epogen, Serostim, Zyprexa, Diflucan, Combivir, and Retrovir [1,3-6]. In addition to the patient safety, counterfeiting has also resulted in economic losses to the established drug manufacturers. This drug companies losses billions of dollars as well as reputation when counterfeit drugs are purchased instead of genuine drugs. At the same time, local economy suffers as counterfeit drug enters the country illegally without paying important duties and sales taxes. The FDA has taken multiple steps to combat this problem [2]. The current laws require every drug to have complete information: drug name, dosage, container size, lots or control numbers. The law also requires information on number of containers, business name and address of all parties involved in the transaction at all levels from manufacturer to the retailer [2]. These steps have decreased the incidents but at the same time added a great deal of complexity for both manufacturers and distributors in maintaining pedigrees given the volume of transactions [3].

\section{Background}

\section{Drug diversion}

Drug diversion is the principal method by which counterfeits enter the legitimate drug market. Before the finished product reaches the retailers, drug products enter several global supply chains that provide opportunities for counterfeiters to taint the product. The raw materials are transported from chemical plant to manufacturing units and later to main distributors, wholesalers and retail pharmacists $[1,3,4]$. The finished product "drug" can get counterfeit at these intermediate levels before its entry into the market. The current system cannot prevent the drugs to pass through supply chain before it reaches the consumer [7]. The major sources of diverted drugs are samples, stolen products, re-imports, own-use pharmacy scam, Medicare and Medicaid fraud, surplus medications and through pharmaceutical representatives that have resulted in gray markets. The other major reason is the difference in price of drugs at global level that encourages gray market where drugs are diverted and then obtained by counterfeiters e.g. the counterfeiting incidents increased in England as the drugs are cheaper in Portugal and Spain [1]. The most alarming problem is the supply chain that is not controlled by the manufacturers or supervised by any regulator nationally. Once the drugs are on the gray market they are degraded, mishandled and relabeled. The contaminated drugs are priced at lower price and attract legitimate wholesalers to make more profits. Recently, internet pharmacy is the common source of counterfeit drugs. The low price of drugs on internet attracts consumers. The World Health Organization (WHO) estimates that $50 \%$ of all medicines sold online are counterfeit $[4,8]$. The Federal Food and Drug Administration (FDA) issued a warning on counterfeit version of Tami flu sold online as its active ingredient oseltamivir was replaced by cloxacillin, an ingredient in the same class of antibiotics as penicillin to make profits [9-11]. According to the Pharmaceutical Security Institute, 1,700 incidents of counterfeit drugs were reported in 2010, triple the number in 2004

*Corresponding author: Tejpreet Chadha, Texas Tech University, Box 43131, Lubbock, TX 79409, USA, E-mail: preeti.chadha@ttu.edu

Received December 21, 2012; Accepted January 25, 2013; Published January 28, 2013

Citation: Chadha T, Ferguson R (2013) RFID: Chromogenic Polymer Opal Film with Seal Could be Adopted as a Sensitive and Effective Technology to Fight against Counterfeit Drugs. Adv Pharmacoepidem Drug Safety 2: 125. doi:10.4172/2167 1052.1000125

Copyright: $\odot 2013$ Chadha T, et al. This is an open-access article distributed under the terms of the Creative Commons Attribution License, which permits unrestricted use, distribution, and reproduction in any medium, provided the original author and source are credited. 
$[4,12]$. The counterfeit drugs will continue to be on internet until the consumers are vigilant and report to the authorities.

This mushrooming challenge of counterfeit drugs continues to expand with the growth of the internet. Private and public must evolve to not only prohibit growth of the criminal enterprise, but to reassure consumers that the quality of medicines is well protected. From 2001 to 2011, the known cases of counterfeit drugs have doubled.

\section{Radio-frequency identification (RFID)}

The Radio Frequency Identification (RFID) technology is a unique identification method using radio waves that communicates with tags that hold digital information in microchips [13]. Counterfeit drugs have become a great challenge to pharmaceutical industry $[12,14,15]$. Due to high economic losses some of them have adopted new technology RFID. The RFID system can be utilized to track and trace the counterfeit medicines. The combination of RFID and GPS was recently introduced by China to track the containers that were travelling between shanghai and savannah [15]. RFID system has not been implemented globally as it can compromise consumer privacy. Besides privacy issues there is also high cost in setting up system e.g. it can cost $\$ 10$ to $\$ 25$ million with no return on investment (ROI) for companies that implement the technology if compliance is the only pursuit. Pfizer Inc. spent \$5 million to implement an RFID system for tracking Viagra [12,14]. The limitation is that governments around the world regulate the frequency spectrum as a result RFID tag may not work in all countries due to the lack of an international uniform standard. This ultimately hinders the use of RFID tags in a global environment. The economic slowdown has created major stress for wholesalers and small scale retailers. The recession created an opportunistic environment for counterfeiters to penetrate more markets with their tainted low cost product that propped up the profit margin for struggling vendors. Right now, companies are challenged to keep their products and supplies moving, manage inventory levels and keep low transportation cost. This makes even more difficult to adopt RFID, because it may influence the retail shelf price.

With the complete implementation of RFID, drug counterfeiters adapted as represented in figure 1 and the case load has continued to rise. Intelligent packaging provides the consumer a role in this war against drugs. This gives a higher level of assurance that product had not been tampered with since bottling and shipping. By hardening the target for drug counterfeiters, a real sense of security is there for the consumer with an intelligent package. Investigators benefit with more time to study raw materials and manufacturing where a drug can be degraded in processing and shipped into the market to defeat consumer protection systems (Figure 2).

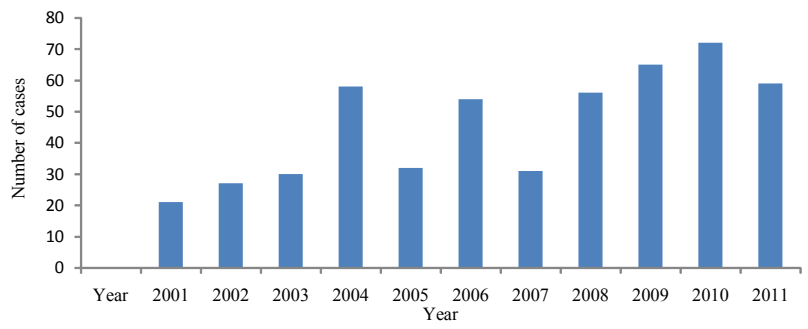

Figure 1: FDA Counterfeit Drug Cases Opened Each Year per thousand (http://www.fda.gov/Drugs/default.htm).

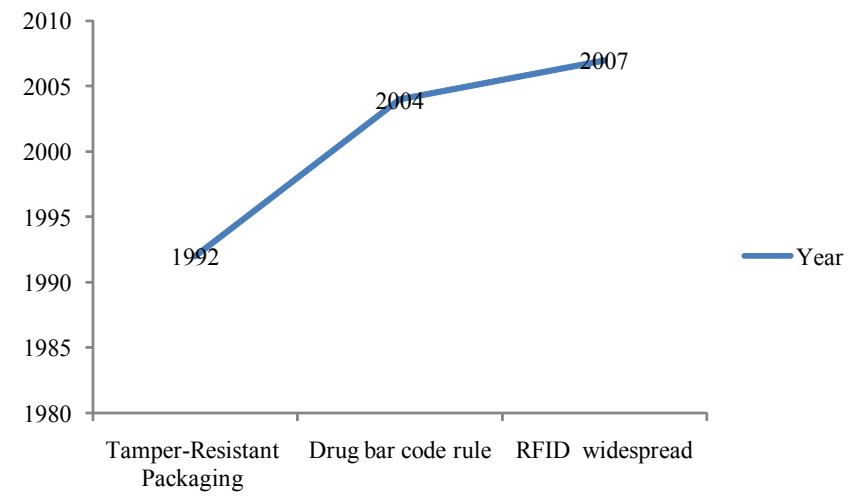

Figure 2: FDA Anti-counterfeit Packaging Technology (http://www.fda.gov/ Drugs/default.htm).

\section{Others}

Mass spectrometer can be used by retailers to verify the materials in a pill. This can cost up to $\$ 150,000$ therefore it is expensive to be used in every drugstore [8]. Many drug companies have started using holograms and barcodes to make their products harder to counterfeit [16]. The counterfeiters have managed to mimic holograms and barcodes and it's difficult for consumer to differentiate between the genuine and counterfeit product.

\section{New approach}

RFID has appeared to be an effective technology but due to initial high set up cost it has not been implemented uniformly [13]. Due to economic slowdown it is difficult for corporations to spend money on RFID. This situation has prompted to look for new approaches that are cheaper and can be used effectively to combat counterfeiting. We suggest the use of simple and sensitive tool that can be used in combination with vacuum seal. This can be effective and affordable strategy that can enhance security and prevent counterfeiters to contaminate drugs.

\section{Active or intelligent packaging}

The package system is considered to be active if it actively changes the condition of the package in order to maintain the quality of the product [17-19]. If the package has ability to sense the environment and monitor the quality of the product and is able to communicate with the consumer, it is considered to be intelligent e.g. time-temperature indicators, toxin indicators [20-22]. The new approach could be use of chromogenic materials that change their optical properties in response to an external stimulus e.g. irradiation of light, change in temperature [22-24]. The change in color in response to a change within the product will be a visual warning and can be easily detected by consumers or government regulatory personnel. The chromogenic material polymer opal films can be used to seal the bottle along with the vacuum seal [25]. These polymers contain crystals that are made of repeating units with optical properties. The range of frequencies that occur causes variations in the light that is reflected from these regions as well as from the nanoparticles embedded between the spheres. The films can produce an intense color that could be influenced by depending on arrangement of spheres and the placement of the nanoparticles $[22,26]$. If the film is used with vaccum seal, it will protect the drug [27]. If someone tries to open the package seal made with this material, orientation of the lattice structure will change the distance between the spheres. This will cause a change in color of film. This would thus alert a customer of possible contamination. The other possible option would be use of conjugated 
Citation: Chadha T, Ferguson R (2013) RFID: Chromogenic Polymer Opal Film with Seal Could be Adopted as a Sensitive and Effective Technology to Fight against Counterfeit Drugs. Adv Pharmacoepidem Drug Safety 2: 125. doi:10.4172/2167-1052.1000125

Page 3 of 3

polymers $[21,22,25]$. The color changes are as result of an external stimulus e.g. exposure to light. Packaging plays an important role as it protects the product against environmental effects as well as enhances security and communicates with the consumer as a marketing tool [22]. The purity and safety of a drug can be affected at various points during its distribution and transportation. Thus, any mishandling of the drug can have a significant impact on its safety and overall quality, especially if the integrity of the package is not maintained. This tool is not as expensive as RFID.

\section{Discussion}

Intelligent packaging provides a visual affirmation at the most elementary level from manufacturer to consumer whether a product has been tampered with. The active intelligent packaging is a sensible tool that alerts manufacturers and consumers about counterfeit drugs [22]. With intelligent packaging as the tip of the drug security spear, the arsenal of security mechanisms limits counterfeiter's accessibility to the supply chain. The regulatory officials have stated that it is almost impossible to differentiate between a genuine and fake drug without a lab test. This makes even more important to protect consumers from counterfeit drugs. The polymer opal film provides a visual warning signal that can be easily detected by everyone. If the film is added to the vacuum seal, it will increase the security of the drug bottle [28]. An interesting future study might attempt to correlate outcome of using chromogenic polymer opal film with vacuum seal. This will not only lead to a greater understanding of its potential but also protect pharmaceutical companies from economic looses by preventing massive recalls in cases where counterfeited versions of their products have resulted in mass casualties.

\section{References}

1. United States. Congress. House. Committee on Government Reform Subcommittee on Criminal Justice DP, and Human Resources (2006) Sick crime: counterfeit drugs in the United States: hearing before the Subcommittee on Criminal Justice, Drug Policy, and Human Resources of the Committee on Government Reform, House of Representatives, One Hundred Ninth Congress, first session, November 1, 2005.

2. (2004) Counterfeit surgical mesh. FDA Consum 38: 2-3.

3. Eban K (2005) Dangerous doses: how counterfeiters are contaminating America's drug supply. (5thedn), Houghton Mifflin Harcourt, USA.

4. Chambliss WG, Carroll WA, Kennedy D, Levine D, Moné MA, et al. (2012) Role of the pharmacist in preventing distribution of counterfeit medications. J Am Pharm Assoc (2003) 52: 195-199.

5. (2003) Recall of counterfeit Lipitor. FDA Consum 37: 3.

6. (2003) Counterfeit Procrit. FDA Consum 37: 5.

7. Schuster EW, Koh, R, Auto-ID Labs: Track and Trace in the Pharmaceutical Supply Chain. Auto-ID Labs, Massachusetts Institute of Technology, Cambridge, MA; 2003.

8. Patil D, Pandit V, Pore S, Chavan C (2012) Fighting counterfeit and substandard drugs at periphery: The utility of basic quality control tests. Pharmacie Globale 3: $1-3$.

9. (2003) FDA announces initiative to curb counterfeit drugs. FDA Consum 37: 6.

10. (2005) Counterfeit drug warning. FDA Consum 39: 5.

11. (2006) Fighting pandemic flu. FDA Consum 40: 3.
12. Singh K, Arora N, Singh I, Garg T, Murthy R (2012) RFID: A trustable security tool in Pharmaceutical Industry. Am J PharmTech 2.

13. (2005) Radiofrequency identification technology: protecting the drug supply. FDA Consum 39: 37

14. Jokela J, Rådestad M, Gryth D, Nilsson H, Rüter A, et al. (2012) Increased Situation Awareness in Major Incidents-Radio Frequency Identification (RFID) Technique: A Promising Tool. Prehosp Disaster Med 27: 81-87.

15. Lin SS, Hung MH, Tsai CL, Chou LP (2012) Development of an Ease-ofUse Remote Healthcare System Architecture Using RFID and Networking Technologies. J Med Syst 36: 3605-3619.

16. (2004) Final rule on bar code labeling. FDA Consum 38: 3

17. Yam KL, Takhistov PT, Miltz J (2005) Intelligent Packaging: Concepts and Applications. J Food Sci 70: R1-R10.

18. Kerry JP, O'Grady MN, Hogan SA (2006) Past, current and potential utilization of active and intelligent packaging systems for meat and muscle-based products: A review. Meat Sci 74: 113-130.

19. De Jong AR, Boumans H, Slaghek T, Van Veen J, Rijk R, et al. (2005) Active and intelligent packaging for food: is it the future? Food Addit Contam 22: 975979 .

20. de Kruijf N N, van Beest M, Rijk R, Sipiläinen-Malm T, Paseiro LP, et al. (2002) Active and intelligent packaging: applications and regulatory aspects. Food Addit Contam 19: 144-162.

21. Mills $A$ (2005) Oxygen indicators and intelligent inks for packaging food. Chem Soc Rev 34: 1003-1011.

22. Feliciano L: Color Changing Plastics for Food Packaging. Ohio State University, Columbus, Ohio.

23. New color-changing technology has potential packaging, Military, Aerospace Applications. In Science Daily; 2007.

24. Avendaño E, Berggren L, Niklasson GA, Granqvist CG, Azens A (2006) Electrochromic materials and devices: Brief survey and new data on optical absorption in tungsten oxide and nickel oxide films. Thin Solid Films 496: 30-36.

25. Pursiainen OL, Baumberg JJ, Winkler H, Viel B, Spahn P (2007) Nanoparticletuned structural color from polymer opals. Opt Express 15: 9553-9561.

26. Lampert CM, Granvist CG (eds). (1990) Large-area chromogenics : materials and devices for transmittance control. SPIE Optical Engineering Press, Bellingham, USA.

27. Lee DS, Yam KL, Piergiovanni L (2008) Food packaging science and technology. Boca Raton, FL: Taylor and Francis Group.

28. Ma C, Taya M, Xu C (2007) Smart sunglasses and goggles based on electrochromic polymers. In UWNews. 